\title{
CuAg and AuAg bimetallic nanoparticles for catalytic and heat transfer applications
}

\author{
Anusha Dsouza ${ }^{1}$ - M. P. Shilpa ${ }^{1}$ - S. C. Gurumurthy ${ }^{1}$ (I) B. S. Nagaraja ${ }^{2} \cdot$ Shridhar Mundinamani $^{3} \cdot$ Koduri Ramam $^{4}$. \\ Murali Gedda ${ }^{5}$ M. S. Murari ${ }^{6}$
}

Received: 16 September 2020 / Accepted: 20 May 2021 / Published online: 12 June 2021

(c) The Author(s) 2021

\begin{abstract}
Bimetallic nanoparticles (BNPs) have drawn significant attention due to their numerous applications. They demonstrate enhanced optical, electrical, thermal, and catalytic properties due to the synergistic effects of monometals present in them. In this work, $\mathrm{CuAg}$ and $\mathrm{AuAg}$ BNPs have been synthesized using a facile and economical chemical reduction method. Optical characterization was carried out using UV-visible spectroscopy, and effect of $\mathrm{pH}$ on optical absorbance was studied. For $\mathrm{CuAg}$ and $\mathrm{AuAg}$ BNPs, optimum pH was observed to be at 9.4 and 6.39, respectively. Morphological investigation confirms the average diameters of $\mathrm{CuAg}$ and $\mathrm{AuAg}$ BNPs were to be $65 \mathrm{~nm}$ and $30 \mathrm{~nm}$, respectively. Photocatalytic property illustrates the reduction of 4-nitrophenol to 4-aminophenol with a 92\% conversion percentage in the presence of CuAg BNPs in 4 min, and rate constant for the reaction was measured to be $8.98 \times 10^{-3} \mathrm{~s}^{-1}$. But for the AuAg BNPs, the conversion percentage was $97 \%$ in $8 \mathrm{~min}$ and rate constant was found to be $7.95 \times 10^{-3} \mathrm{~s}^{-1}$. Thermal conductivity and viscosity measurements of the nanofluids obtained with $\mathrm{CuAg}$ and AuAg BNPs have ascertained them to be efficient candidates for the heat transfer and catalytic applications.
\end{abstract}

S. C. Gurumurthy

gurumurthy.s.c@gmail.com

$\triangle$ Koduri Ramam

ramamk@udec.cl

1 Nanomaterials and Polymer Physics Lab, Department of Physics, Manipal Institute of Technology, Manipal Academy of Higher Education, Manipal, 576104 Udupi, Karnataka, India

2 Department of Physics, NMAM Institute of Technology (Visvesvaraya Technological University), Nitte, Karkala, Belagavi 574110, Karnataka, India

3 Department of Physics, Siddaganga Institute of Technology, Tumakuru 572103, Karnataka, India

4 Laboratorio de Nanocompuestos, Departamento de Ingeniería de Materiales (DIMAT), Facultad de Ingeniería(FI), Universidad de Concepción (UdeC), Concepción, Chile

5 Division of Physical Sciences and Engineering, KAUST Solar Centre, King Abdullah University of Science and Technology, Thuwal, 23955-6900 Makkah, Saudi Arabia

6 DST PURSE Lab, Mangalore University, Mangalagangotri 574 199, India 


\section{Graphic abstract}

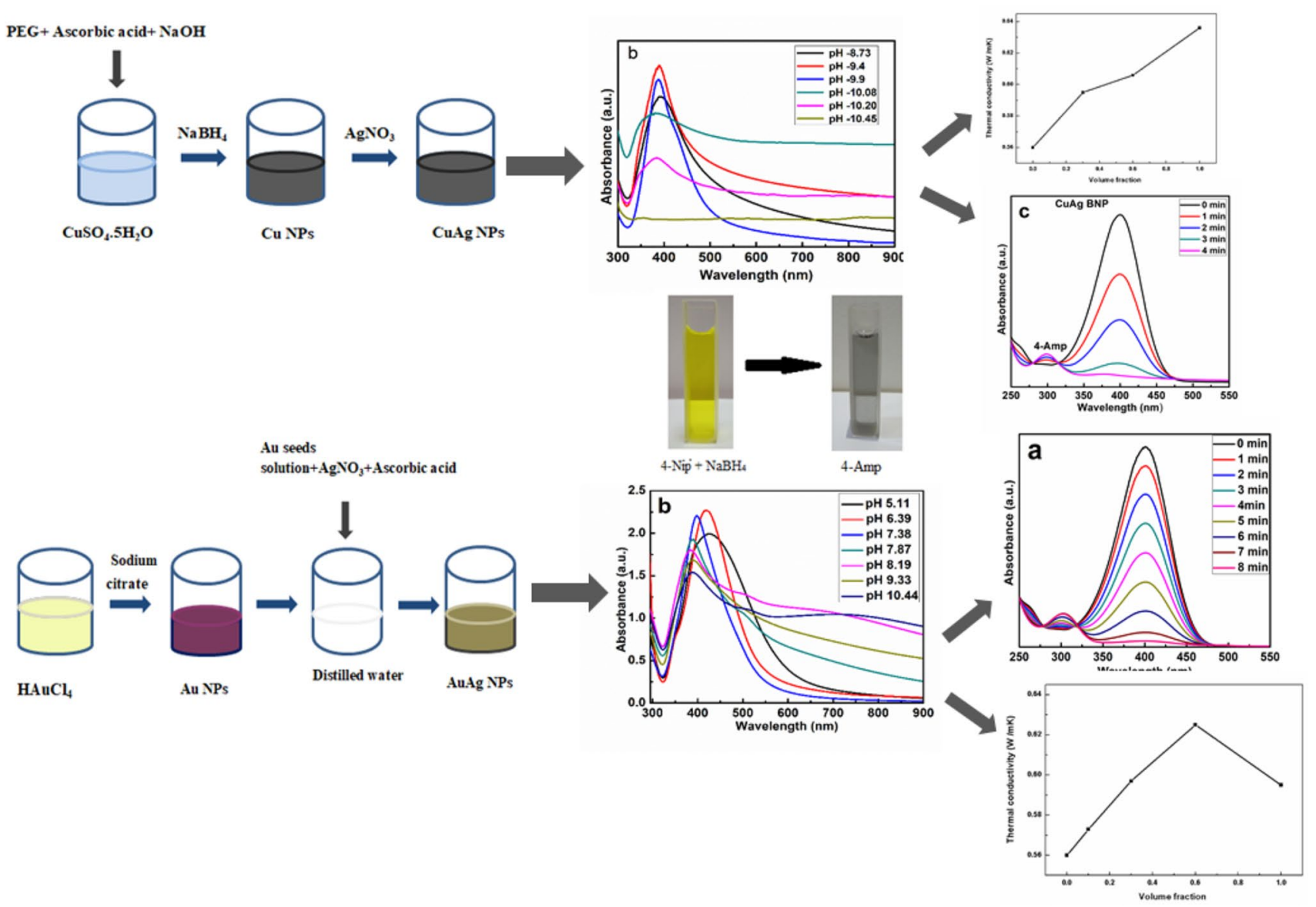

Keywords Bimetallic nanoparticles · Thermal conductivity $\cdot$ Viscosity $\cdot$ Catalytic activity $\cdot$ Optical properties $\cdot$ Gold Silver

\section{Introduction}

Nanostructured materials have prevailed superior characteristics over their bulk counterparts in the contemporary times owing to their unique and exceptional properties. They possess potential applications in various fields such as catalysis, optoelectronics, antibacterial activity, and electronics (Srinoi et al. 2018). Among them, BNPs are well known and gained great importance and interest with their enhanced optical, electrical, and catalytic properties compared to the singlecomponent nanoparticles (NPs) due to their composition and synergistic effects (Sharma et al. 2015; Suwannarat et al. 2018). In comparison with the metal NPs, the BNPs are cost-effective, provided the materials, synthesis, and characteristics are leveraged well with their potential usage in electrical, catalytic, and heat transfer applications. Therefore, there is an increasing demand for the low-cost and applicative BNPs Au-Ag (Ferreira et al. 2020), $\mathrm{Cu}-\mathrm{Ni}$ (Kim et al.
2016; Hashemizadeh and Biglari 2018), and Pt-Pd (Wang et al. 2018) in which the synthesis method such as thermal decomposition, chemical reduction, hydrothermal, microemulsion, microwave irradiation, sol-gel, sonochemical, and radiolytic plays a vital role.

One of the well-known applications of NPs is catalysis, where NPs are used to enhance the rate of the reaction. Aromatic nitro compounds are of great importance in industries, since most of the dyes, drugs, pesticides, etc., are manufactured using these compounds. Still, the reduction of aromatic nitro compounds to amino compounds before their disposal to the environment is also equally crucial since aromatic nitro compounds are toxic (Suwannarat et al. 2018). Metallic NPs are successfully used in the catalytic reduction of 4-nitrophenol to 4-aminophenol to a certain extent of success. Comparatively, BNPs have good catalytic activity than monometallic NPs because the work function or electronic levels of two elements align together to enhance 
the electronic charge shift, which is responsible for catalysis. Thus, the combinatorial effect of two elements in BNPs yields better catalytic activity than their corresponding monometallic NPs (Toshima 2008).

Pangkita Deka et. al. employed in situ generated Cu NPs as a catalyst for the reduction of 4-nitrophenol to 4-aminophenol in the presence of $\mathrm{NaBH}_{4}$ very efficiently at room temperature with good recyclability up to four cycles (Deka et al. 2014). Tanur Sinha and M. Ahmaruzzaman reported the green synthesis of $\mathrm{Cu}$ NPs using fish scales of Labeo rohita for the catalytic degradation of methylene blue (96\%) from aqueous solution (Sinha and Ahmaruzzaman 2015). Sijo Francis et. al. synthesized Ag and Au NPs using the herb Naregamia alata by microwave-assisted reduction, and NPs have efficiently reduced the dyes such as eosin Y, methyl red, and 4-nitrophenol in the presence of $\mathrm{NaBH}_{4}$ (Francis et al. 2017). Nikesh Gupta et. al. prepared gold, silver, and platinum NPs using tannic acid as reducing agent. Silver NPs showed enhanced photocatalytic activity toward the degradation of methyl orange when compared to the gold and platinum NPs in the presence of $\mathrm{NaBH}_{4}$ (Gupta et al. 2011). Nurafaliana Berahim et. al. studied the photocatalytic property of the $\mathrm{Au}-\mathrm{Ag}$ BNPs prepared via seed colloidal technique. Size-dependent enhanced catalytic reduction of 4-nitrophenol into 4-aminophenol is observed compared to corresponding their monometallic NPs (Berahim et al. 2018). Muhammad Ismail et. al. synthesized ginger rhizome powder-based bimetallic photocatalysts, i.e., copper-silver $(\mathrm{Cu}-\mathrm{Ag} / \mathrm{GP})$, copper-nickel $(\mathrm{Cu}-\mathrm{Ni} / \mathrm{GP})$, and nickel-silver (Ni-Ag/GP) for the reduction of 2-nitrophenol (2-NP), 4-nitrophenol (4-NP), methyl orange (MO), congo red (CR), and rhodamine $\mathrm{B}(\mathrm{RhB}) . \mathrm{Cu}-\mathrm{Ag} / \mathrm{GP}$ and $\mathrm{Cu}-\mathrm{Ni} /$ GP displayed excellent catalytic activity for the reduction of all tested organic compounds, and the prepared NPs can be used for the reduction of mixture of dyes (Ismail et al. 2018).

Along with the catalytic applications, heat transfer applications are very common in chemical processing industries by adapting several fluids (liquids) to carry out the process. These applications mainly depend on the fluid properties such as thermal conductivity, density, viscosity, and specific heat (Yu and Choi 2003; Garg et al. 2008; Hamed Mosavian et al. 2010). Water, ethylene glycol, polypropylene, polyvinylpyrrolidone, and mineral oils are some of the base fluids. Thermal conductivity of base fluid can be enhanced by the inclusion of metal NPs, whereas its heat transfer ability is boosted by incorporating the BNPs. However, other fluid properties such as density, viscosity, and specific heat should be taken care of.

Garg, J. et al. reported that 2 vol\% copper in ethylene glycol would lead to a $38 \%$ enhancement in the thermal conductivity of ethylene glycol (Garg et al. 2008). Saterlie et al. showed that there was a $48 \%$ enhancement in the thermal conductivity of deionized water when $1.0 \mathrm{vol} \%$ copper nanofluid was inserted in it (Saterlie et al. 2011). L. Godson et. al. showed that thermal conductivity of water can be increased by $80 \%$ by adding 0.9 vol\% silver nanofluid at an average temperature of $70{ }^{\circ} \mathrm{C}$ (Godson et al. 2010). They witnessed that enhancement of thermal conductivity and viscosity is holding a proportional relationship at elevated temperatures for silver nanofluid. Nevertheless, the viscosity enhancement was less compared to the thermal conductivity, which is a necessary factor for the heat transfer application. Natallia Shalkevich et. al. have produced gold nanofluid with a wide range of particle sizes, i.e., $2-45 \mathrm{~nm}$, and concentrations, i.e., $0.0025-1 \mathrm{vol} \%$, observing significant enhancement in thermal conductivity of water reaching its highest value of $1.4 \%$ for NPs size $40 \mathrm{~nm}$ with particle concentration of $0.11 \%$ (Shalkevich et al. 2010). Jisha John et. al. followed a green synthesis approach for the preparation of gold nanofluids using the plant extracts Piper nigrum, Cinnamomum verum, and Syzygium samarangense leaf (John et al. 2015). Increased thermal conductivity of the base fluid (water) was observed in case of star-shaped particles, followed by bean and spherical NPs with the decrease in the specific heat capacity. Min-Sheng Liu et. al. prepared copper NPs by the chemical reduction method, and it efficiently improved the thermal conductivity of water (Liu et al. 2006). There was $23.8 \%$ enhancement in thermal conductivity when the volume concentration of $\mathrm{Cu}$-water nanofluids was $0.1 \%$. $\mathrm{M}$. Meena Kumari et. al. carried out a green synthesis technique for the preparation of Au-Ag BNPs using fruit juice of pomegranate (Meena Kumari et al. 2015). Both core-shelland alloy-like nanostructures were formed based on the different molar ratios of gold and silver ions. There was an enhancement in thermal conductivity of base fluid (water) from 21 to $72 \%$ when the volume concentration of nanofluid increases from 25 to $100 \%$ at 303 K. Sujoy Das and M M. Ghosh synthesized Ag-Cu alloy NPs via wet chemical method at room temperature and dispersed them in water and ethylene glycol (Das and Ghosh 2019). Thermal conductivity of the nanofluid increased almost linearly with wt $\%$ recording thermal conductivity enhancement as $9.6 \%$ at 0.26 $\mathrm{wt} \%$ loading, and for ethylene glycol-based nanofluids, it is as $24.2 \%$ at $1.5 \mathrm{wt} \%$ loading. Moreover, both water and ethylene glycol-based nanofluids are stable in static condition for at least 35 days.

In our work, we have employed chemical reduction process to synthesize $\mathrm{CuAg}$ and AuAg BNPs by simply controlling the composition, size, shape, and structure of the NPs by altering the $\mathrm{pH}$, temperature, reducing agent, stabilizing agent, and precursor. Here, reducing agents are meant to reduce the metal ions to its zero-valent state (Natsuki et al. 2015). We have analyzed its catalytic behavior by reducing 4-nitrophenol to 4-aminophenol as a model reaction for the reduction of aromatic compounds. Owing to the physical, chemical, and thermal properties of copper, gold, and silver 
NPs, we have tested the thermal conductivity and viscosity of $\mathrm{CuAg}$ and $\mathrm{AuAg}$ BNPs to know the combined effect of monometallic NPs in the enhancement of the thermal conductivity of the base fluid.

\section{Experimental section}

\section{Materials}

Copper sulfate pentahydrate $\left(\mathrm{CuSO}_{4} .5 \mathrm{H}_{2} \mathrm{O}, 99 \%\right)$, polyethylene glycol (PEG), sodium hydroxide ( $\mathrm{NaOH}, 98 \%)$, silver nitrate $\left(\mathrm{AgNO}_{3}, 99 \%\right)$, trisodium citrate $(99 \%)$, and 4-nitrophenol (98\%) were procured from Loba Chemie Pvt. Ltd. Ascorbic acid (99\%) and sodium borohydride $\left(\mathrm{NaBH}_{4}, 98 \%\right)$ were purchased from Sigma-Aldrich. Tetrachloroauric acid $\left(\mathrm{HAuCl}_{4}\right)$ was procured from Spectrochem Pvt. Ltd. All the chemicals were used without any further purification.

\section{Synthesis of CuAg BNPs}

$\mathrm{CuAg}$ BNPs were prepared using seed synthesis method. Here, polyethylene glycol (PEG) (0.02 M), ascorbic acid $(0.02 \mathrm{M})$, and $\mathrm{NaOH}(0.1 \mathrm{M})$ were added sequentially to $\mathrm{CuSO}_{4} .5 \mathrm{H}_{2} \mathrm{O}(0.01 \mathrm{M})$ solution under continuous stirring for one hour, followed by the addition of $\mathrm{NaBH}_{4}(0.1 \mathrm{M})$. A yellow-colored solution which turned black after some time indicates the formation of $\mathrm{Cu}$ NPs. An aqueous solution of $\mathrm{AgNO}_{3}(0.01 \mathrm{M})$ was added to the seed solution and stirred for $10 \mathrm{~min}$ to form $\mathrm{CuAg}$ BNPs.

\section{Synthesis of AuAg BNPs}

AuAg BNPs were synthesized by the seed colloidal technique (Ko and Chang 2014; Berahim et al. 2018). For this, we have added $1 \mathrm{ml}$ sodium citrate $(38.8 \mathrm{mM})$ to $10 \mathrm{ml}$ aqueous solution of $\mathrm{HAuCl}_{4}(1 \mathrm{mM})$ under vigorous stirring at $100{ }^{\circ} \mathrm{C}$ temperature. The appearance of dark red color indicates the formation of Au NPs, but the stirring and heating were continued for 10 more minutes to complete the reduction reaction. $2.5 \mathrm{ml}$ of Au seed solution was added to $8 \mathrm{ml}$ of distilled water, and then, $1 \mathrm{ml}$ of sodium citrate $(38.8 \mathrm{mM})$ was added to the resulted solution with stirring at room temperature. After $10 \mathrm{~min}$ of stirring, $1.2 \mathrm{ml}$ of silver nitrate $(10 \mathrm{mM})$ and $0.4 \mathrm{ml}$ of ascorbic acid $(100 \mathrm{mM})$ were added in sequence, and the stirring was continued for $30 \mathrm{~min}$.

\section{Characterization}

Optical studies of the prepared samples were carried out using a Shimadzu-1800 UV-Vis spectrophotometer.
Morphological and elemental analysis was carried out using a field emission scanning electron microscope and an energy-dispersive X-ray diffraction analyser (FESEM; Carl Zeiss; EVO-18), accordingly. Structural analysis was performed by an X-ray diffractometer (XRD) (Rigaku Miniflex 600).

\section{Catalytic reaction}

The catalytic activity of these BNPs was studied by the reduction of 4-nitrophenol. One milligram of bimetallic nanopowder was dispersed in $4 \mathrm{ml}$ of distilled water out of which $400 \mu \mathrm{l}$ of solution was added to $3 \mathrm{ml}$ of distilled water along with $40 \mu \mathrm{l}$ aqueous solution of 4-nitrophenol $(0.01 \mathrm{M})$ in a quartz cuvette. The sample was analyzed immediately after adding $200 \mu \mathrm{l}$ of $\mathrm{NaBH}_{4}(0.5 \mathrm{M})$ to the cuvette with the spectrophotometer. The progress of the reaction was periodically checked until the solution turned transparent, which indicates the completion of the reduction process.

\section{Thermal conductivity and viscosity measurements}

Thermal conductivity measurement was taken using KD2 Pro setup from Decagon Devices, Inc., which works on the hot-wire principle. Initially, the instrument was calibrated using glycerin, and then, the thermal conductivity of water and other samples ( 0.3 volume fraction, 0.6 volume fraction, and 1.0 volume fraction) was measured. The maximum error in measurement was $5 \%$. The viscosity of the samples was measured using a MCR rheometer from AntonPaar with a shear rate of $600 \mathrm{~s}^{-1}$. The reactions that may occur during the synthesis of CuAg BNPs are as follows (Trinh et al. 2015):

$$
\begin{aligned}
& \mathrm{Cu}^{2+}+\mathrm{C}_{6} \mathrm{H}_{8} \mathrm{O}_{6} \rightarrow \mathrm{Cu}^{0}+\mathrm{C}_{6} \mathrm{H}_{6} \mathrm{O}_{6}+2 \mathrm{H}^{+} \\
& \mathrm{Cu}^{2+}+2 \mathrm{BH}_{4}^{-}+6 \mathrm{H}_{2} \mathrm{O} \rightarrow \mathrm{Cu}^{0}+7 \mathrm{H}_{2}+2 \mathrm{~B}(\mathrm{OH})_{3} \\
& \mathrm{Cu}^{0}+2 \mathrm{Ag}^{+} \rightarrow 2 \mathrm{Ag}^{0}+\mathrm{Cu}^{2+} \\
& 2 \mathrm{Ag}^{+}+\mathrm{C}_{6} \mathrm{H}_{8} \mathrm{O}_{6} \rightarrow 2 \mathrm{Ag}^{0}+\mathrm{C}_{6} \mathrm{H}_{6} \mathrm{O}_{6}+2 \mathrm{H}^{+} \\
& 2 \mathrm{Ag}^{+}+2 \mathrm{BH}_{4}^{-}+6 \mathrm{H}_{2} \mathrm{O} \rightarrow 2 \mathrm{Ag}^{0}+7 \mathrm{H}_{2}+2 \mathrm{~B}(\mathrm{OH})_{3} .
\end{aligned}
$$

The reactions that occur during the synthesis of AuAg BNPs are as follows (Kumar et al. 2007; Suriati and Mariatti 2014): 
$2 \mathrm{AuCl}_{4}^{-}+3\left(\mathrm{CH}_{2} \mathrm{COOH}\right)_{2} \mathrm{C}(\mathrm{OH}) \mathrm{COO}^{-} \rightarrow 2 \mathrm{Au}^{0}+8 \mathrm{Cl}^{-}+3\left(\mathrm{CH}_{3}\right)_{2} \mathrm{C}=\mathrm{O}+9 \mathrm{CO}_{2}+3 \mathrm{H}^{+}$and

$4 \mathrm{Ag}^{+}+\mathrm{C}_{6} \mathrm{H}_{5} \mathrm{O}_{7} \mathrm{Na}_{3}+2 \mathrm{H}_{2} \mathrm{O} \rightarrow 4 \mathrm{Ag}^{0}+\mathrm{C}_{6} \mathrm{H}_{5} \mathrm{O}_{7} \mathrm{H}_{3}+3 \mathrm{Na}^{+}+\mathrm{H}^{+}+\mathrm{O}_{2}$

\section{Results and discussion}

\section{Optical studies}

It is well known that the surface plasmon resonance (SPR) of the NPs depends on the size, shape, and type of the material. The optical behavior of the prepared BNPs was studied using a UV-visible spectrometer. The absorbance spectrum of $\mathrm{CuAg}$ BNPs is shown in Fig. 1a. CuAg BNPs showed absorbance peak at $389 \mathrm{~nm}$, while $\mathrm{Cu}$ and $\mathrm{Ag}$ NPs are exhibiting at 574 and $410 \mathrm{~nm}$, respectively (Pellarin et al. 2015; Cao et al. 2019; Jolly et al. 2021). The influence of $\mathrm{pH}$ on the optical properties of CuAg BNPs is depicted in Fig. 1b. The pH of the solution was varied by adding different amounts of $\mathrm{NaOH}$ during the preparation of BNPs. This study analyzes the effect on the absorbance spectra of the synthesized BNPs. Variation of the $\lambda_{\max }$ and maximum absorbance with $\mathrm{pH}$ are shown in Fig. 1c, d, and it is observed that the optical properties of NPs tuned with the variation in $\mathrm{pH}$ of the solution, where the $\mathrm{CuAg}$ BNPs showed maximal absorbance at $\mathrm{pH}$ 9.4. However, the absorbance intensity decreases with a further increase in the $\mathrm{pH}$ value. Oxidation reaction and aggregation of NPs may occur for the $\mathrm{pH}$ below and above 10, respectively. Hence, the $\mathrm{pH}$ range between 8 and 9 is desirable in order to synthesize the NPs anticipated for designated applications. Within this $\mathrm{pH}$ range, electrostatic repulsion between the nanoclusters increases by reducing the aggregation tendency of the nanoclusters (Alqadi et al. 2014; Anigol et al. 2017).

The optical absorbance spectra of AuAg BNPs and their effect with respect to the $\mathrm{pH}$ on optical spectra are depicted in Fig. 1e, f. Absorbance peak is traced out at $420 \mathrm{~nm}$ for BNPs (Yang et al. 2008), while individual NPs are displaying at $522 \mathrm{~nm}$ and $410 \mathrm{~nm}$, respectively (Meena Kumari et al. 2015). Variation of $\lambda_{\max }$ with $\mathrm{pH}$ is shown in Fig. $1 \mathrm{~g}$. $\lambda_{\max }$ was found to be blue shifted, indicating that with the increase in $\mathrm{pH}$ the particle size decreases (Park et al. 2019). This is because the solution becomes alkaline as electrostatic repulsion between the nanoclusters increases, which reduces the aggregation tendency of the nanoclusters (Anigol et al. 2017). As shown in Fig. 1h, maximum absorption at a particular wavelength was decreased and also the broadening of the curve was detected over $\mathrm{pH} 6.39$. It may be due to the formation of non-uniform NPs with different sizes absorbing light of different wavelengths.

\section{Morphological studies}

SEM images of both AuAg (Fig. 2a) and CuAg (Fig. 2b) BNPs in comparison with their individual NP entities reveal their surface morphology as shown in Fig. 2. Their uniform distribution accounts for the active role of surfactant polyethylene glycol preventing the agglomeration of NPs. The average diameter of $\mathrm{AuAg}$ and $\mathrm{CuAg}$ BNPs is 30 and $65 \mathrm{~nm}$, whereas the $\mathrm{Au}$ (Fig. 2c), $\mathrm{Ag}$ (Fig. 2d), and Cu (Fig. 2e) NPs possess the values as 20,50 , and $56 \mathrm{~nm}$, correspondingly. These tiny NPs are expected to contribute optimal thermal conductivity allowing them to be potential candidates for the heat transfer applications. The EDS mapping of $\mathrm{CuAg}$ in Fig. $2 \mathrm{f}$ and AuAg in Fig. $2 \mathrm{~g}$ confirms the presence of
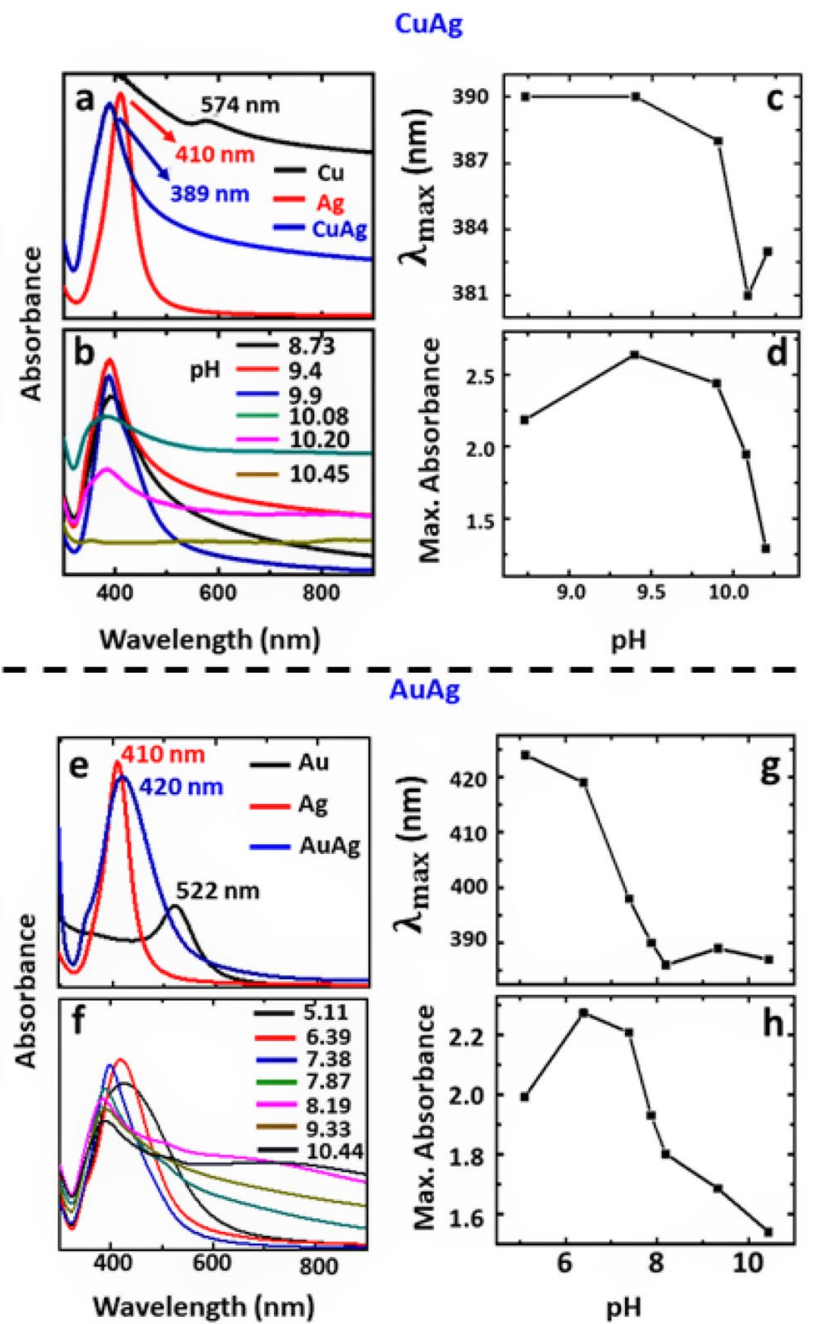

Fig. 1 Optical absorption spectra of $\mathrm{CuAg}(\mathbf{a}-\mathbf{d})$ and $\mathrm{AuAg}(\mathbf{e}-\mathbf{h})$ BNPs. (a) Absorbance of $\mathrm{Cu}, \mathrm{Ag}$, and $\mathrm{CuAg}$ BNPs and (b) absorbance with $\mathrm{pH}$ variation. $\mathrm{pH}$ dependence of (c) $\lambda_{\max }$ and (d) maximum absorbance. Similar to $\mathrm{CuAg}$, (e) absorbance of $\mathrm{Au}, \mathrm{Ag}$, and $\mathrm{AuAg}$ BNPs and (f) absorbance with $\mathrm{pH}$ variation. $\mathrm{pH}$ dependence of (g) $\lambda_{\max }$ and (h) maximum absorbance 

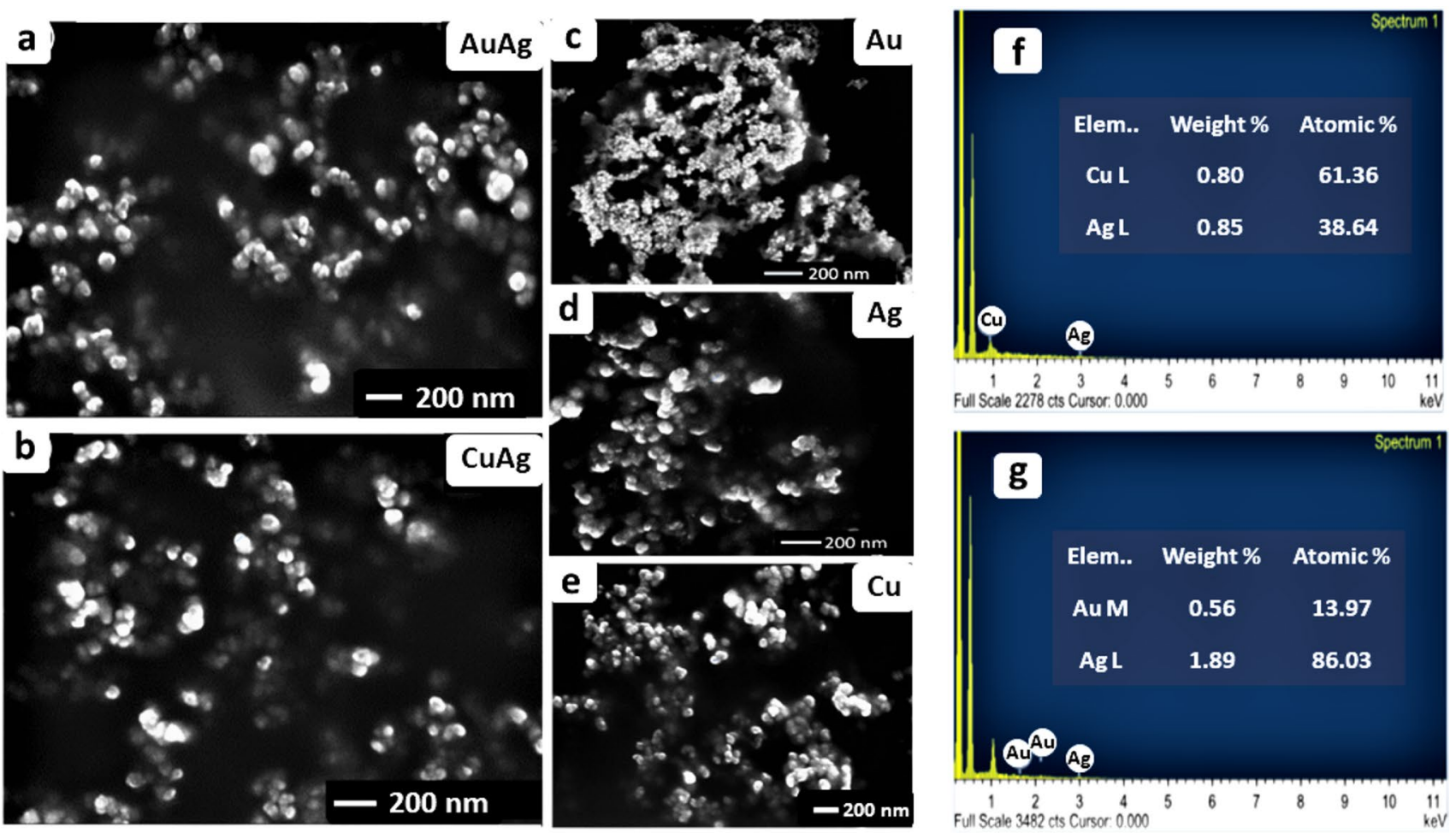

Fig. 2 FESEM images of (a) AuAg, (b) CuAg, (c) Au, (d) Ag, and (e) Cu BNPs. EDS images of (f) CuAg and (g) AuAg BNPs with weight percentages

respective elements with respect to their weight percentages in BNPs that are present in the nanofluid.

\section{Structural studies}

Figure 3a,b represents the XRD patterns of AuAg and $\mathrm{CuAg}$ BNPs revealing the formation of well-crystalline nature closer to nano-realms. Distinguishing the Au and Ag XRD peaks is impracticable as their lattice parameters barely mismatch. However, in the above morphological studies by FESEM-EDS, we can clearly observe the respective metallic concentrations. The XRD patterns of AuAg (Fig. 3a), CuAg (Fig. 3b) BNPs are indexed by their corresponding powder diffraction files of $\mathrm{Cu}$ (PDF\# 89-2838) and Ag (PDF\# 04-0783). Simultaneously, the two diffraction peaks of $\mathrm{Cu}$ (at $42^{\circ}, 73.4^{\circ}$ ) and four peaks of $\mathrm{Ag}$ (at $37.84^{\circ}, 44.04^{\circ}, 64.22^{\circ}, 77.22^{\circ}$ ) denoted in the figures are confessing the face-centered cubic crystalline orientation. The presence of the peaks at $2 \theta=36.22^{\circ}$ and $2 \theta=61.64^{\circ}$ corresponding to the respective (111) and (220) planes is due to the presence of oxidized phase of Cu NPs (Cuprous Oxide JCPDS \# 65-3288). The structural and morphological studies of these high crystalline BNPs make them competent enough
Fig. 3 XRD patterns of (a) $\mathrm{AuAg}$ and (b) $\mathrm{CuAg}$ BNPs
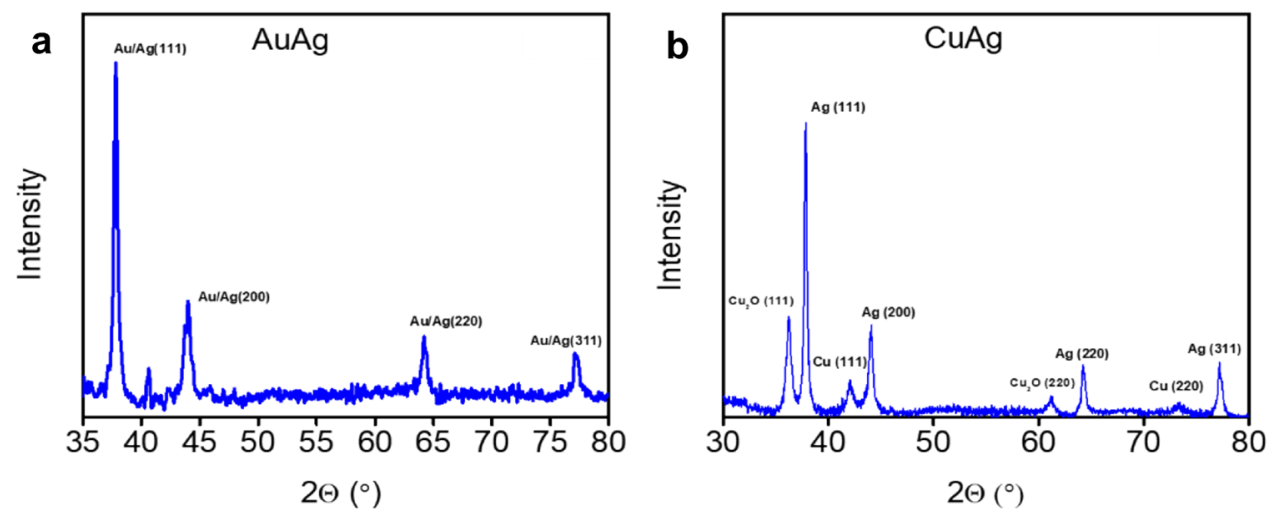
for heat transfer applications offering optimum thermal conductivity (Chen et al. 2013; Holden et al. 2014).

\section{Catalytic studies of CuAg BNPs}

Catalysis is one of the major applications of the NPs, and we have carried out the catalytic activity of prepared $\mathrm{CuAg}$ BNPs for the reduction of 4-nitrophenol in the presence of $\mathrm{NaBH}_{4}$. Figure 4a shows the UV-visible absorption spectra for the reduction of 4-nitrophenol in the presence of $\mathrm{NaBH}_{4}$ alone. The decrease in intensity of absorption peak observed at $400 \mathrm{~nm}$ is attributed to the reduction of 4-nitrophenol in the presence of $\mathrm{NaBH}_{4}$, demonstrating $23 \%$ reduction of 4-nitrophenol after 60 min as shown in Fig. 4b (Berahim et al. 2018). Next, Fig. 4c portrays the absorption spectra for the reduction of 4-nitrophenol in the presence of $\mathrm{CuAg}$ BNPs as a catalyst and $\mathrm{NaBH}_{4}$ as reducing agent. In the presence of these BNPs, the reduction from 4-nitrophenol to 4-aminophenol was observed in $4 \mathrm{~min}$ and the color of the solution turned from yellow to colorless. The new peak at $300 \mathrm{~nm}$ is attributed to the absorption peak of 4-aminophenol (Berahim et al. 2018). Rate constant of the chemical reactions was calculated from $\ln \left(\mathrm{A}_{0} / \mathrm{A}_{t}\right)$ versus time plot for both $\mathrm{NaBH}_{4}$ and $\left(\mathrm{NaBH}_{4}+\mathrm{CuAg}\right.$ catalyst), as shown in the inset of Fig. 4b and in Fig. 4d. The rate constant of $\mathrm{NaBH}_{4}$ alone was found to be $6.99 \times 10^{-5} \mathrm{~s}^{-1}$, and in the presence of $\mathrm{CuAg}$, it was $8.98 \times 10^{-3} \mathrm{~s}^{-1}$. Figure $4 \mathrm{e}$ shows the conversion percentage of nitrophenol to aminophenol in the presence
Fig. 4 (a) UV-visible spectra of reducing the 4-nitrophenol in the presence of $\mathrm{NaBH}_{4}$, (b) reduction percentage of 4-nitrophenol with $\ln \left(\mathrm{A}_{0} / \mathrm{A}_{\mathrm{t}}\right)$ versus time plot. (c) Reducing the 4-nitrophenol in the presence of CuAg BNPs. (d) Reduction percentage of 4-nitrophenol with $\ln \left(\mathrm{A}_{0} / \mathrm{A}_{\mathrm{t}}\right)$ versus time plot. Rate constant of the reactions (b (inset), e) is shown as $\ln \left(\mathrm{A}_{0} /\right.$ $\mathrm{A}_{\mathrm{t}}$ ) versus time plot. (f) Color change from yellow (before reduction) to transparent (after the completion of reduction)
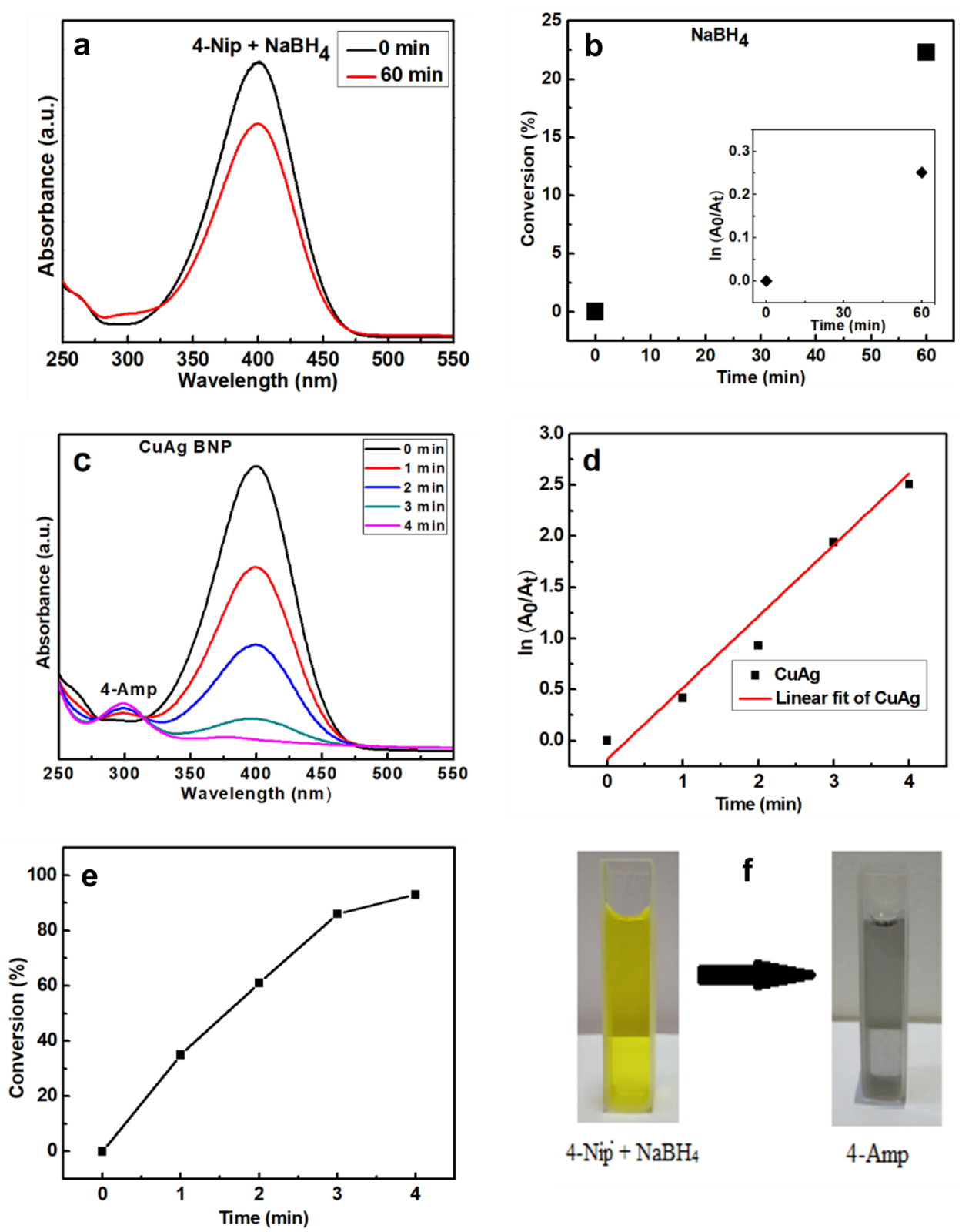

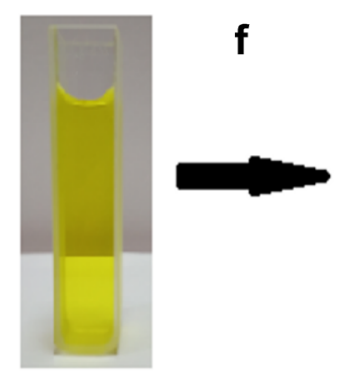

4-Nip $+\mathrm{NaBH}_{4}$

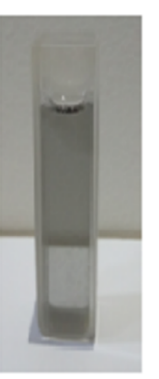

4-Amp 
of $\mathrm{CuAg}$ BNPs, and Fig. $4 \mathrm{f}$ depicts the color of the solution before (4-Nip $+\mathrm{NaBH}_{4}$ ) and after reduction (4-Amp). There was $92 \%$ conversion of 4-nitrophenol to 4-aminophenol using $\mathrm{CuAg}$ BNPs. The conversion efficiency of $\mathrm{CuAg}+\mathrm{NaBH}_{4}$ is significantly higher, indicating that the BNPs can be effective catalysts for the dye reduction.

\section{Catalytic studies of AuAg BNPs}

Similar to the $\mathrm{CuAg}$, the catalytic activity of AuAg BNPs was studied by catalyzing the reduction of 4-nitrophenol to 4-aminophenol. Figure 5a shows the absorption spectra of the reduction of 4-nitrophenol in the presence of AuAg BNPs. At the beginning of the reduction process, the peak was observed at $400 \mathrm{~nm}$, which is attributed to the absorption peak of 4-nitrophenolate. The intensity of the peak at $400 \mathrm{~nm}$ was found to decrease with time and a new peak was formed at $300 \mathrm{~nm}$. Color change from yellow to transparent indicates the completion of reduction process. The rate constant of the chemical reaction was calculated from $\ln \left(\mathrm{A}_{0} /\right.$ $A_{t}$ ) versus time plot shown in Fig. 5b, and the corresponding value was found to be $7.95 \times 10^{-3} \mathrm{~s}^{-1}$. Figure $5 \mathrm{c}$ shows the conversion percentage of nitrophenol to aminophenol in the presence of AuAg BNPs yielding about 97\% conversion in $8 \mathrm{~min}$ permitting them to effectively reduce the aromatic nitro compounds.

\section{Thermal conductivity and viscosity studies of $\mathrm{CuAg}$}

Thermal conductivity and viscosity of $\mathrm{CuAg}$ nanofluid were measured at room temperature by varying the concentration of $\mathrm{CuAg}$ nanofluid from 0 to $100 \%$ in the base fluid water. Figure 6 illustrates the plot of thermal conductivity and viscosity at a different volume fraction, and it is found to increase proportionally with the concentration of NPs in the base fluid. Table 1 provides the thermal conductivity as well as viscosity values at a different volume fraction of nanofluid.

Increasing the nanofluid concentration from $30 \mathrm{vol} \%$ to 100 vol\%, we can evidence the enhancement in thermal conductivity is from 2 to $8 \%$, whereas the increment in viscosity is in the range of $21 \%$ to $72 \%$. The increment in thermal conductivity can be attributed to the Brownian motion of NPs, but the change in viscosity is because of their suspension in nanofluid. These results indicate that $\mathrm{CuAg}$ BNPs are potential candidates for the heat transfer applications.

\section{Thermal conductivity and viscosity studies of AuAg}

In analogy to $\mathrm{CuAg}$, thermal conductivity and viscosity of AuAg nanofluid were measured at room temperature by varying the concentration of $\mathrm{AuAg}$ nanofluid from 0 to $100 \%$. The plot of thermal conductivity and viscosity at a
Fig. 5 (a) UV-visible spectra of reduction of 4-nitrophenol in the presence of $\mathrm{AuAg}$, (b) $\ln \left(\mathrm{A}_{0} / \mathrm{A}_{\mathrm{t}}\right)$ versus time plot, $(\mathbf{c})$ percentage conversion versus time plot, (d) color change from yellow (before reduction) to transparent (after complete reduction)
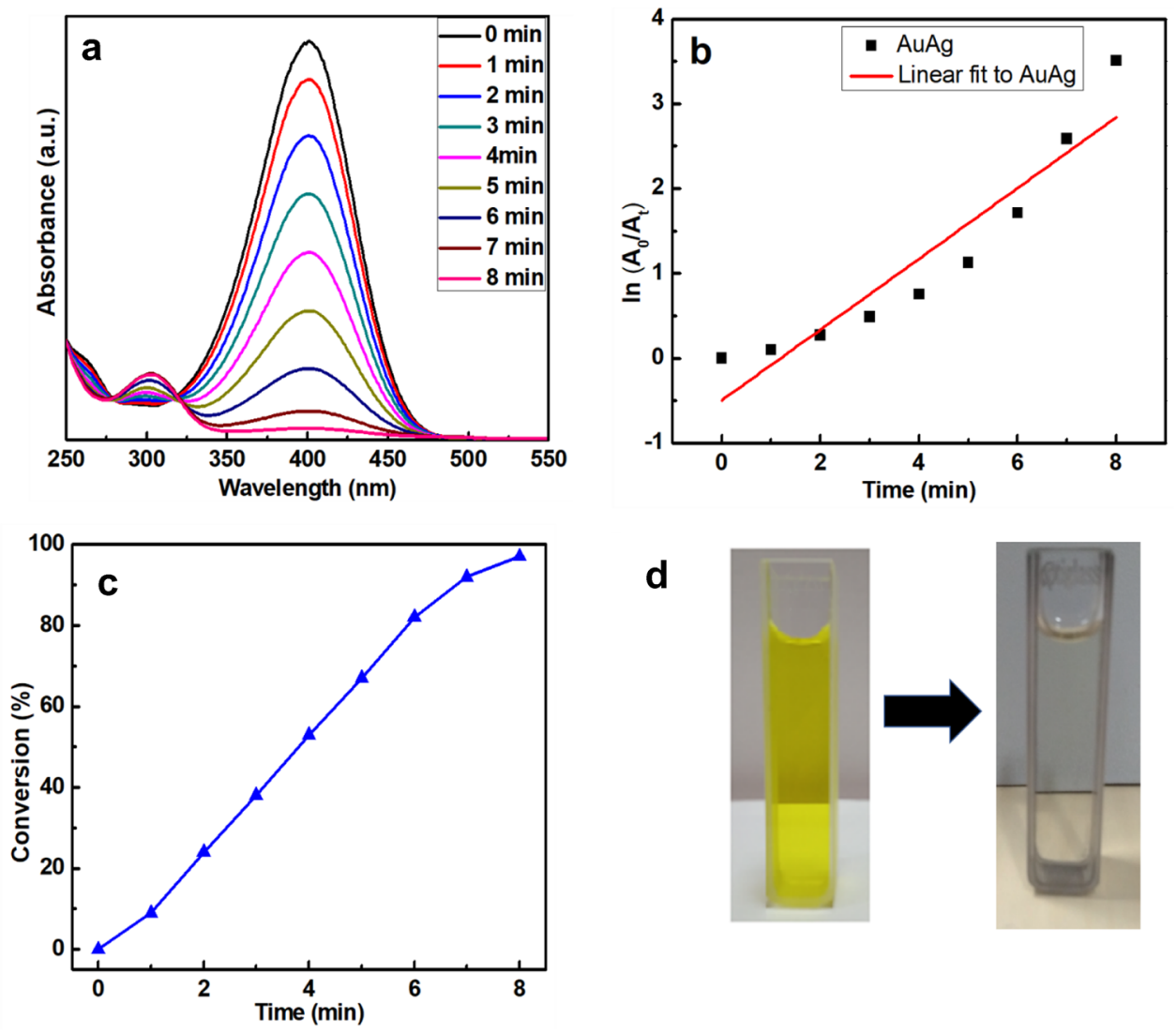
Fig. 6 (a) Thermal conductivity at different volume fractions, (b) viscosity at different volume fractions, for the CuAg BNPs
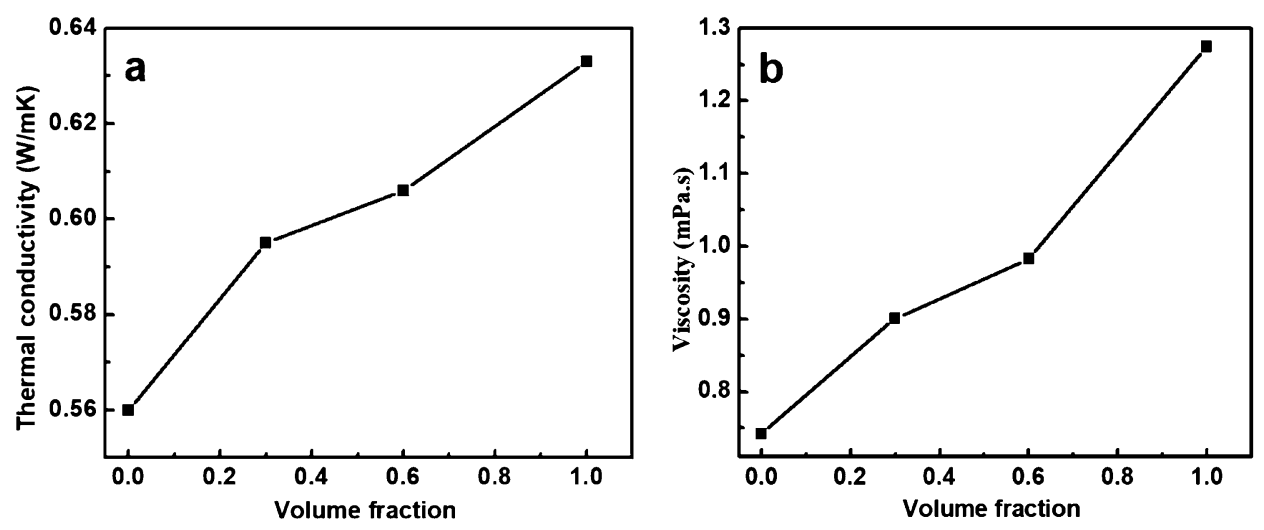

Table 1 Values of thermal conductivity and viscosity at different volume percents of $\mathrm{CuAg}$ nanofluid

\begin{tabular}{lll}
\hline $\begin{array}{l}\text { Vol \% of nanofluid (with } \\
\text { colloidal NPs) }\end{array}$ & $\begin{array}{l}\text { Thermal conductiv- } \\
\text { ity (W/mK) }\end{array}$ & Viscosity (mPa.s) \\
\hline 0 (water) & 0.560 & 0.742 \\
30 & 0.595 & 0.901 \\
60 & 0.606 & 0.983 \\
100 & 0.633 & 1.274 \\
\hline
\end{tabular}

different volume fraction of nanofluid is shown in Fig. 7. Both thermal conductivity and viscosity were found to increase with the concentration of nanofluid in the base fluid. However, after 0.6 volume fraction, thermal conductivity tends to decrease, which may be due to the agglomeration of NPs, which hampers the conduction [22].

Table 2 shows the thermal conductivity as well as viscosity values at different volume fractions of nanofluid. Nearly $7 \%$ enhancement was observed with thermal conductivity reaching a maximum at $60 \mathrm{vol} \%$ of nanofluid, and an increase in viscosity was found to be $6 \%$ approximately. In resemblance to the $\mathrm{CuAg}$ BNPs, the increase in thermal conductivity can be attributed to the Brownian motion of NPs, while the viscosity to the suspension of
NPs enables them to be potential candidates for heat transfer applications.

\section{Conclusion}

In this work, the $\mathrm{CuAg}$ and $\mathrm{AuAg}$ BNPs were successfully prepared via chemical reduction method. CuAg BNPs showed a characteristic absorbance peak at $389 \mathrm{~nm}$ and the optimum absorbance has been attained at $\mathrm{pH}$ 9.4. In the case of AuAg BNPs, the absorbance peak was found at $420 \mathrm{~nm}$, having maximum absorption at $\mathrm{pH}$ 6.39. Structural examination unveils their spherical nature and the presence of bimetallic composition is evinced by EDS analysis. The

Table 2 Values of thermal conductivity and viscosity at different volume percents of AuAg nanofluid

\begin{tabular}{lll}
\hline $\begin{array}{l}\text { Vol \% of nanofluid (with } \\
\text { colloidal NPs) }\end{array}$ & $\begin{array}{l}\text { Thermal conductiv- } \\
\text { ity (W/mK) }\end{array}$ & Viscosity (mPa.s) \\
\hline 0 (water) & 0.560 & 0.769 \\
10 & 0.573 & 0.855 \\
30 & 0.597 & 0.752 \\
60 & 0.625 & 0.819 \\
100 & 0.595 & 0.821 \\
\hline
\end{tabular}

Fig. 7 (a) Thermal conductivity at different volume fractions, (b) viscosity at different volume fractions, for the AuAg BNPs
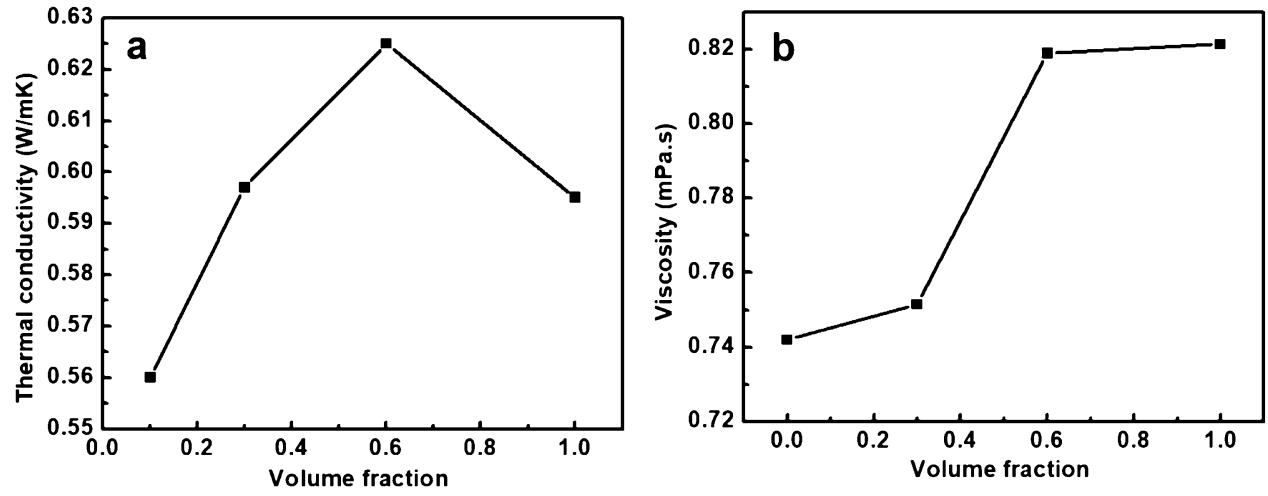
catalytic activity of both BNPs realizes better reducing ability of nitrophenol to aminophenol, and the rate constants of the reaction were found to be $8.98 \times 10^{-3} \mathrm{~s}^{-1}(\mathrm{CuAg})$ and $7.95 \times 10^{-3} \mathrm{~s}^{-1}$ (AuAg), which is higher compared to either pure gold or silver NPs. Therefore, the prepared BNPs are optimal candidates for better and faster reduction of 4-nitrophenol. Thermal conductivity and viscosity of base fluid were found to increase with the concentration of nanofluid. Enhancement in thermal conductivity was found to be $8 \%$ for 100 vol $\%$ of nanofluid, and viscosity increased about $72 \%$ for CuAg BNPs. Thus, 7\% enhancement in thermal conductivity was obtained for $60 \mathrm{vol} \%$ nanofluid in the presence of AuAg BNPs, and the viscosity has nearly attained $6 \%$.

Acknowledgements The authors are grateful to Mangalore University DST-PURSE Laboratory for facilitating the FESEM and for the support provided by the Manipal Academy of Higher Education (MIT-2017, 2020), Karnataka. The authors are grateful to Ms. Indira R Hiremath and Dr. Srivathsava Surabhi for their contribution in the revision process. The author Koduri Ramam is greatly indebted to Universidad de Concepción (UdeC), Chile, for its huge support and facilities. The authors also acknowledge Fondecyt Regular Project No. 1140420, Programa Fondo Nacional de Desarrollo Científico y Tecnológico (FONDECYT) de la Agencia Nacional de Investigación y Desarrollo, Chile.

Funding Open access funding provided by Manipal Academy of Higher Education, Manipal.

Open Access This article is licensed under a Creative Commons Attribution 4.0 International License, which permits use, sharing, adaptation, distribution and reproduction in any medium or format, as long as you give appropriate credit to the original author(s) and the source, provide a link to the Creative Commons licence, and indicate if changes were made. The images or other third party material in this article are included in the article's Creative Commons licence, unless indicated otherwise in a credit line to the material. If material is not included in the article's Creative Commons licence and your intended use is not permitted by statutory regulation or exceeds the permitted use, you will need to obtain permission directly from the copyright holder. To view a copy of this licence, visit http://creativecommons.org/licenses/by/4.0/.

\section{References}

Alqadi MK, Abo Noqtah OA, Alzoubi FY et al (2014) PH effect on the aggregation of silver nanoparticles synthesized by chemical reduction. Mater Sci Pol 32:107-111. https://doi.org/10.2478/ s13536-013-0166-9

Anigol LB, Charantimath JS, Gurubasavaraj PM (2017) Effect of Concentration and $\mathrm{pH}$ on the size of silver nanoparticles synthesized by green chemistry. Org. Med. Chem. Int. J 3:555622. https://doi. org/10.19080/OMCIJ.2017.03.555622

Berahim N, Basirun W, Leo B, Johan M (2018) Synthesis of Bimetallic Gold-Silver (Au-Ag) Nanoparticles for the Catalytic Reduction of 4-Nitrophenol to 4-Aminophenol. Catalysts 8:412. https://doi.org/ $10.3390 /$ catal 8100412

Chen Z, Mochizuki D, Maitani MM, Wada Y (2013) Facile synthesis of bimetallic $\mathrm{Cu}-\mathrm{Ag}$ nanoparticles under microwave irradiation and their oxidation resistance. Nanotechnology 24:265602. https://doi. org/10.1088/0957-4484/24/26/265602

Das S, Ghosh MM (2019) An experimental investigation on thermal conductivity and stability of aqueous and nonaqueous nanofluids containing $\mathrm{Ag}-\mathrm{Cu}$ alloy nanoparticles. Mater Res Express 6:115027. https://doi.org/10.1088/2053-1591/ab4457

Deka P, Deka RC, Bharali P (2014) In situ generated copper nanoparticle catalyzed reduction of 4-nitrophenol. New J Chem 38:1789-1793. https://doi.org/10.1039/C3NJ01589K

Ferreira E, Kharisov B, Vázquez A et al (2020) Tuning the nonlinear optical properties of Au@ Ag bimetallic nanoparticles. J Mol Liq 298:112057. https://doi.org/10.1016/j.molliq.2019.112057

Francis S, Joseph S, Koshy EP, Mathew B (2017) Synthesis and characterization of multifunctional gold and silver nanoparticles using leaf extract of: Naregamia alata and their applications in the catalysis and control of mastitis. New J Chem 41:1428814298. https://doi.org/10.1039/C7NJ02453C

Garg J, Poudel B, Chiesa M et al (2008) Enhanced thermal conductivity and viscosity of copper nanoparticles in ethylene glycol nanofluid. J Appl Phys 103:074301. https://doi.org/10.1063/1. 2902483

Godson L, Raja B, Lal DM, Wongwises S (2010) Experimental investigation on the thermal conductivity and viscosity of silver-deionized water nanofluid. Exp Heat Transf 23:317-332. https://doi.org/ 10.1080/08916150903564796

Gupta N, Singh HP, Sharma RK (2011) Metal nanoparticles with high catalytic activity in degradation of methyl orange: An electron relay effect. J Mol Catal A Chem 335:248-252. https://doi.org/ 10.1016/j.molcata.2010.12.001

Hamed Mosavian MT, Zeinali Heris S, Etemad SG, Nasr Esfahany M (2010) Heat transfer enhancement by application of nano-powder. J Nanoparticle Res 12:2611-2619. https://doi.org/10.1007/ s11051-009-9840-6

Hashemizadeh SA, Biglari M (2018) Cu: Ni bimetallic nanoparticles: facile synthesis, characterization and its application in photodegradation of organic dyes. J Mater Sci Mater Electron 29:1302513031. https://doi.org/10.1007/s10854-018-9424-2

Holden MS, Nick KE, Hall M et al (2014) Synthesis and catalytic activity of pluronic stabilized silver-gold bimetallic nanoparticles. RSC Adv 4:52279-52288. https://doi.org/10.1039/C4RA07581A

Ismail M, Khan MI, Khan SB et al (2018) Green synthesis of plant supported $\mathrm{Cu}-\mathrm{Ag}$ and $\mathrm{Cu}-\mathrm{Ni}$ bimetallic nanoparticles in the reduction of nitrophenols and organic dyes for water treatment. J Mol Liq 260:78-91. https://doi.org/10.1016/j.molliq.2018.03.058

John J, Thomas L, Kumar BR et al (2015) Shape dependent heat transport through green synthesized gold nanofluids. J Phys D Appl Phys 48:335301. https://doi.org/10.1088/0022-3727/48/33/335301

Jolly A, Uday A, Gurumurthy SC et al (2021) Effect of silane/aminebased dopants on polymer-metal interaction of sub-surface silver nanoparticulate films. J Mater Sci Mater Electron 32:2719-2730. https://doi.org/10.1007/s10854-020-04995-z

Jun Natsuki, Toshiaki Natsuki, Yoshio Hashimoto (2015) A review of silver nanoparticles: Synthesis methods, properties and applications. Int J Mater Sci Appl 4:325-332. https://doi.org/10.11648/j. ijmsa.20150405.17

Kim HJ, Song M, Jeong JH et al (2016) Highly efficient and stable cupronickel nanomesh electrode for flexible organic photovoltaic devices. J Power Sources 331:22-25. https://doi.org/10.1016/j. jpowsour.2016.09.024

Ko FH, Chang YC (2014) Aptamer based surface enhanced Raman scattering detection of adenosine using various core sizes of Au-Ag core-shell nanoparticles. RSC Adv 4:26251-26257. https://doi.org/10.1039/C4RA02762K

Kumar S, Gandhi KS, Kumar R (2007) Modeling of Formation of Gold Nanoparticles by Citrate Method $†$. Ind Eng Chem Res 46:31283136. https://doi.org/10.1021/ie060672j 
Liu MS, Lin MCC, Tsai CY, Wang CC (2006) Enhancement of thermal conductivity with $\mathrm{Cu}$ for nanofluids using chemical reduction method. Int J Heat Mass Transf 49:3028-3033. https://doi.org/10. 1016/j.ijheatmasstransfer.2006.02.012

Meena Kumari M, Jacob J, Philip D (2015) Green synthesis and applications of Au-Ag bimetallic nanoparticles. Spectrochim ActaPart A Mol Biomol Spectrosc 137:185-192. https://doi.org/10. 1016/j.saa.2014.08.079

Park S, Lee WJ, Park S et al (2019) Reversibly pH-responsive gold nanoparticles and their applications for photothermal cancer therapy. Sci Rep 9:20180. https://doi.org/10.1038/s41598-019-56754-8

Pellarin M, Issa I, Langlois C et al (2015) Plasmon spectroscopy and chemical structure of small bimetallic $\mathrm{Cu}(1-\mathrm{x}) \mathrm{Agx}$ clusters. J Phys Chem C 119:5002-5012. https://doi.org/10.1021/jp511671m

Saterlie M, Sahin H, Kavlicoglu B et al (2011) Particle size effects in the thermal conductivity enhancement of copper-based nanofluids. Nanoscale Res Lett 6:217. https://doi.org/10.1186/ 1556-276X-6-217

Shalkevich N, Escher W, Bürgi T et al (2010) On the thermal conductivity of gold nanoparticle colloids. Langmuir 26:663-670. https:// doi.org/10.1021/la9022757

Sharma G, Naushad M, Kumar A et al (2015) Lanthanum/Cadmium/ Polyaniline bimetallic nanocomposite for the photodegradation of organic pollutant. Iran Polym J 24:1003-1013. https://doi.org/10. 1007/s13726-015-0388-2

Sinha T, Ahmaruzzaman M (2015) Green synthesis of copper nanoparticles for the efficient removal (degradation) of dye from aqueous phase. Environ Sci Pollut Res 22:20092-20100. https://doi.org/ 10.1007/s11356-015-5223-y

Srinoi P, Chen YT, Vittur V et al (2018) Bimetallic nanoparticles: enhanced magnetic and optical properties for emerging biological applications. Appl Sci 8:1106

G. Suriati, M. Mariatti AA (2014) Synthesis of silver nanoparticles by chemical reduction method: effect of reducing agent and surfactant concentration. Int J Automot Mech Eng 10:1920-1927. https://doi.org/10.15282/ijame.10.2014.9.0160

Suwannarat K, Thongthai K, Ananta S, Srisombat L (2018) Synthesis of hollow trimetallic $\mathrm{Ag} / \mathrm{Au} / \mathrm{Pd}$ nanoparticles for reduction of 4-nitrophenol. Colloids Surf A Physicochem Eng Asp 540:73-80. https://doi.org/10.1016/j.colsurfa.2017.12.046

Toshima N (2008) Capped bimetallic and trimetallic nanoparticles for catalysis and information technology. Macromol Symp 270:2739. https://doi.org/10.1002/masy.200851004

Trinh DC, My T, Dang D, Huynh KK (2015) Synthesis of Cu core Ag shell nanoparticles using chemical reduction method. Adv Nat Sci Nanosci Nanotechnol 6:025018. https://doi.org/10.1088/20436262/6/2/025018

Van Cao P, Surabhi S, Quoc VD et al (2019) Broadband tunable plasmonic substrate using self-assembled gold-silver alloy nanoparticles. Curr Appl Phys 19:1245-1251. https://doi.org/10.1016/j. cap.2019.08.009

Wang H, Sheng L, Zhao X et al (2018) One-step synthesis of Pt-Pd catalyst nanoparticles supported on few-layer graphene for methanol oxidation. Curr Appl Phys 18:898-904. https://doi.org/10. 1016/j.cap.2018.04.006

Yang Y, Shi J, Kawamura G, Nogami M (2008) Preparation of Au-Ag, $\mathrm{Ag}-\mathrm{Au}$ core-shell bimetallic nanoparticles for surface-enhanced Raman scattering. Scr Mater 58:862-865. https://doi.org/10. 1016/j.scriptamat.2008.01.017

Yu W, Choi SUS (2003) The role of interfacial layers in the enhanced thermal conductivity of nanofluids: a renovated Maxwell model. J Nanoparticle Res 5:167-171. https://doi.org/10.1023/A:10244 38603801

Publisher's Note Springer Nature remains neutral with regard to jurisdictional claims in published maps and institutional affiliations. 